Gut, 1983, 24, 16-19

\title{
Biliary excretion of enterokinase in rats: studies in alcoholic rats with fatty liver
}

\author{
D A W GRANT, T R TERRY, and J HERMON-TAYLOR
}

From the Department of Surgery, St George's Hospital Medical School, London

SUMMARY Ethanol-associated fatty liver was induced in rats fed a nutritionally deficient liquid diet containing $36 \%$ of total calories as ethanol. Control rats received the same diet with sucrose substituted isocalorically for ethanol. After 40 days, hepatic lipid content of the ethanolmaintained animals was four-fold greater than controls and ultrastructural changes in hepatocytes were well established. Clearance of intravenously administered human enterokinase from the circulation as well as bile flow were, however, the same in both groups. The proportion of enterokinase appearing in catalytically active form in bile after intravenous injection was substantially greater in the ethanol-maintained animals than the isocaloric controls; the difference was highly significant $(\mathrm{p}<0.001)$ and reached two- to four-fold after 70 days on the diet. These findings would suggest that the ability of hepatocytes to degrade enterokinase cleared from the blood may be bypassed or impaired by prolonged ethanol consumption and a deficient diet. Catalytically active enterokinase in bile may participate in the development of some types of acute necrotising pancreatitis.

In an earlier study we proposed that a critical event in the aetiology of alcohol-induced acute necrotising pancreatitis may be the transfer into bile of small amounts of catalytically active enterokinase sequestered from the proximal small intestine into portal blood. ${ }^{1}$ A crucial factor in this proposal was the demonstration that intravenously administered enterokinase was excreted in catalytically active form in the bile of both normal rats and rats that had been drinking $20 \%(\mathrm{v} / \mathrm{v})$ ethanol for one year. The kinetics of enterokinase excretion were similar to those described for other serum-derived proteins. ${ }^{2}$ The proportion of intravenously administered enterokinase secreted in bile was $1-2 \%$ in both normal and ethanol-maintained rats when up to six successive doses of enzyme were given at 90 minute intervals. When the enzyme was injected every 30 minutes the proportion of administered enterokinase appearing in bile of ethanol-maintained rats was higher than in weight-matched normal controls. The difference was, however, not great, probably because $20 \%$ ethanol with a nutritionally adequate solid diet did not produce sufficiently marked changes in liver function.

The present study describes the clearance from

Received for publication 13 April 1982 blood and subsequent biliary excretion of intravenously administered human enterokinase in rats which progressively developed fatty livers and other evidence of hepatocyte damage by being maintained on a nutritionally inadequate liquid diet in which $36 \%$ of total calories were provided by ethanol. ${ }^{3}$ Animals receiving this diet were compared at intervals with weight-matched pair-fed control animals which received an identical diet, except that sucrose was isocalorically substituted for ethanol.

\section{Methods}

DIET

The vitamin, mineral, fat, and amino-acid constituents of the diet described by Lieber $e t a l^{3}$ were supplied ready-mixed by BP Nutrition (UK) Ltd, Witham, Essex CM8 3AB. Vitamin and fatfree casein was used as the protein source, as its amino-acid composition was comparable with the published diet. A nutritionally depleted diet sufficient to maintain body weight but not growth was made up by liquidising $45 \mathrm{~g}$ of the solid constituents in $500 \mathrm{ml}$ warm tap-water. This was added to $436 \mathrm{ml}$ water containing $100 \mathrm{~g}$ sucrose and the mixture was made up to 1 litre by the addition of $64 \mathrm{ml}$ ethanol (equivalent to $50 \mathrm{~g} / \mathrm{l}$ ). The diet 
contained approximately $22 \%$ of total calories as fat and protein, $42 \%$ as sucrose, and $36 \%$ as ethanol. The control diet had sucrose isocalorically substituted for ethanol by adding $190 \mathrm{~g}$ of the sugar per litre of diet.

Individually caged female Wistar rats weighing between $175-200 \mathrm{~g}$ were divided into two groups of 20. Rats drinking the ethanol-impregnated diet were introduced to the diet over a period of six days by progressively increasing the ethanol content to 50 $\mathrm{g} / \mathrm{l}$. Once established on this diet the other 20 rats were pair-fed the same amount of the control diet as their experimental counterparts had consumed on the previous day. Animals were weighed every five days; two rats in the experimental group were removed from the study because of failure to accept the diet.

\section{ENTEROKINASE}

Human enterokinase was purified to homogeneity as previously described. ${ }^{4}$ The enzyme was assayed in rat serum and bile using the synthetic substrate glycyl-L-tetra-aspartyl-L-lysyl- $\beta$-naphthylamide at a final $\mathrm{Zn}^{2+}$ concentration of $2.5 \mathrm{mM}$. $^{5}$

\section{ANIMAL STUDIES}

Four rats from each group were tested on days 10 , 20,40 , and 70 for their ability to clear intravenously administered enterokinase from the circulation and subsequently to excrete it into bile. The bile duct and femoral vein were cannulated as previously described. ${ }^{1}$ One rat in each group of four received three intravenous doses at 90 minute intervals of 15 $\mu \mathrm{g}$ human enterokinase in $0.5 \mathrm{ml}$ saline; $0.3 \mathrm{ml}$ systemic blood samples were collected at one, two, five, 10, and 20 minutes after administration of the first and last dose. Hepatic bile was collected as 15 minute samples over the 4.5 hour experimental period. In a similar experiment a second rat from each group of four received three doses of $7.5 \mu \mathrm{g}$ enterokinase. The two remaining rats from each group received three intravenous doses at 30 minute intervals of either $7.5 \mu \mathrm{g}$ or $15 \mu \mathrm{g}$ human enterokinase; blood and bile samples were collected as described.

\section{LIVER ANALYSIS}

At the end of each experiment liver biopsies were taken from each rat and fixed in $10 \%$ formalin for histological examination. Additional material was finely minced and fixed in $3 \%$ ice-cold gluteraldehyde for electron microscopy. The remainder was divided into three weighed portions of $1-1.5 \mathrm{~g}$ each and stored in a chloroform:methanol:water mixture $(85: 14: 1)$ at $4^{\circ} \mathrm{C}$ before estimation of total lipids by the method of Folch et al. ${ }^{6}$
STATISTICAL ANALYSIS

The significance of apparent differences in the proportion of intravenously administered human enterokinase secreted in bile of ethanol-maintained and control groups was tested using a four-way factorial analysis of variance.

\section{Results}

The lipid content of the livers (mg lipid/g tissue \pm 1 SD) of the chronic ethanol-maintained and control rats respectively was $100 \pm 26$ and $66 \pm 26$ after 10 days, $107 \pm 35$ and $40 \pm 6$ after 20 days, $243 \pm 31$ and $61 \pm 19$ after 40 days, and $186 \pm 57$ and $41 \pm 13$ after 70 days on the nutritionally deficient diet, confirming the development of changes previously described by Lieber et al. ${ }^{78}$ Fat deposition in the livers of ethanol-maintained rats was gross on light microscopy, and ultrastructural changes in hepatocytes including fragmentation of rough endoplasmic reticulum, hyaline deposition, swelling of mitochondria, and damage to bile ductules was obvious by day 40 . These ultrastructural changes were not seen in control animals. The volume of bile produced during the tests was apparently unaffected, the mean flow rate being $460 \pm 70 \mu \mathrm{l} / \mathrm{h}$ in ethanol-maintained rats, and $488 \pm 104 \mu \mathrm{l} / \mathrm{h}$ in controls. The half-life of enterokinase in the blood ( $<2.5$ minutes) and the completion of enterokinase excretion in bile ( $<1$ hour) was the same for the ethanol-maintained and control animals.

The proportion of the intravenously administered doses of human enterokinase secreted in the bile of chronic ethanol-maintained and control rats after $10,20,40$, and 70 days on the nutritionally deficient diet is shown in the Table. The proportion of the enzyme appearing in the bile of ethanol-maintained animals was considerably greater than in the isocaloric control group; the difference was highly significant $(p<0.001$, variance ratio $(F) 25.8)$ and by day 70 , two to four times as much enterokinase was found in the bile of the ethanolic rats compared with their pair-fed controls.

\section{Discussion}

Human enterokinase is a large molecule with an apparent molecular weight of about $300000 .^{9}$ It is itself particularly resistant to proteolysis ${ }^{9} 10$ and is one of the most heavily glycosylated enzymes known. ${ }^{911}$ The enzyme might be expected to persist in the circulation for a considerable time. Previous studies have, however, shown that this is not the case, and that the half-life ( $\left.t \frac{1}{2}\right)$ of both the human and murine enzymes in the circulation of mice is about $2 \frac{1}{2}$ minutes; ${ }^{12}$ a similar $t \frac{1}{2}$ has been found in the 
Table Mean percentage of three intravenous injections of human enterokinase secreted in bile of chronic ethanolmaintained and control rats fed a nutritionally deficient liquid diet ${ }^{*}$

\begin{tabular}{|c|c|c|c|c|c|c|c|c|}
\hline \multirow{3}{*}{$\begin{array}{l}\text { Days on } \\
\text { diet }\end{array}$} & \multicolumn{4}{|c|}{ Chronic ethanol-maintained rats } & \multicolumn{4}{|c|}{ Isocaloric pair-fed control rats } \\
\hline & \multicolumn{2}{|c|}{ Injection every $30 \mathrm{~min}$ of } & \multicolumn{2}{|c|}{ Injection every 90 min of } & \multicolumn{2}{|c|}{ Injection every 30 min of } & \multicolumn{2}{|c|}{ Injection every $90 \mathrm{~min}$ of } \\
\hline & $7.5 \mu g$ & $15 \mu g$ & $7.5 \mu g$ & $15 \mu g$ & $7.5 \mu g$ & $15 \mu g$ & $7.5 \mu g$ & $15 \mu g$ \\
\hline 10 & 1.9 & $1 \cdot 8$ & $2 \cdot 0$ & $1 \cdot 8$ & $0 \cdot 64$ & 0.96 & $1 \cdot 8$ & $1 \cdot 3$ \\
\hline 20 & $1 \cdot 3$ & $1 \cdot 9$ & 1.9 & $1 \cdot 5$ & ND & $1 \cdot 1$ & 1.6 & $1 \cdot 3$ \\
\hline 40 & $4 \cdot 2$ & 1.8 & $1 \cdot 8$ & 2.9 & $2 \cdot 5$ & $1 \cdot 0$ & 0.81 & $0 \cdot 83$ \\
\hline 70 & $3 \cdot 5$ & $2 \cdot 15$ & $2 \cdot 2$ & $1 \cdot 5$ & 0.9 & $0 \cdot 85$ & $1 \cdot 3$ & $0 \cdot 83$ \\
\hline
\end{tabular}

* See text for experimental details. $p<0.001$, variance ratio $(F) 25.8$ for difference between experimental and control groups.

Enterokinase as $\mu \mathrm{g}$ of enzyme protein. ND $=$ not determined.

rat $^{1}$ and guinea-pig. Immunofluorescent studies have identified the enzyme in hepatocytes after intravenous administration. ${ }^{12}$ As enterokinase persists in the circulation after periodate oxidation of its peripheral sugars, ${ }^{12}$ it seemed likely that its rapid clearance from blood is dependent on specific recognition of its carbohydrate moiety by hepatocyte receptors in a manner similar in principle to that previously described for the elimination of asialoglycoproteins. ${ }^{13-15}$ In the presence of normal liver function a small proportion of circulating enzyme appears in bile in active form. Distortion of liver architecture in experimentally induced $\left(\mathrm{CCl}_{4}\right)$ cirrhosis prolongs the $t \frac{1}{2}$ of enterokinase in the circulation and reduces biliary excretion. ${ }^{1}$

The present study shows that, in the presence of unequivocal evidence of ethanol-associated liver damage in rats (and in the absence of cirrhosis), there is a substantial and significant rise in the amount of circulating enterokinase appearing in the bile in catalytically active form. Unlike the findings in cirrhotic animals, ${ }^{1}$ clearance of the enzyme from the circulation appeared normal, and it seems reasonable to conclude that access to the sinusoidal surface of the hepatocytes and their ability to take up the enzyme from blood was unaffected. Involvement of Kupffer cells in the uptake of intact glycoprotein cannot, however, be excluded. ${ }^{2}{ }^{16}$ Bile flow and the time course of enterokinase excretion in bile appeared unchanged by the development of an ethanol-damaged fatty liver. The substantial increase in biliary excretion of active enterokinase in ethanol-maintained animals would suggest that the ability of their hepatocytes to degrade enterokinase may have been bypassed ${ }^{17}$ or impaired. ${ }^{18}$ If catalytically active enterokinase appears in human bile under pathophysiological conditions, it may, in appropriate circumstances, participate in the development of acute necrotising pancreatitis whose association with fatty liver is well described. ${ }^{19}{ }^{20} \mathrm{It}$ is interesting to note that alcohol-induced acute nesrotising pancreatitis is more often associated clinically with reversible fatty liver than with cirrhosis. ${ }^{19}$

The authors gratefully acknowledge the help of $\mathrm{Dr}$ G Uff, Department of Histopathology, St George's Hospital Medical School, in the preparation of the histological sections and $\operatorname{Dr} \mathbf{J}$ Foster, British Industrial Biological Research Association, for the processing of the electron micrographs. Statistical calculations were kindly performed by Dr Martin Bland, lecturer in statistics. Financial support was given by the St George's Hospital Medical Research Committee and the Wellcome Trust. Mr T R Terry held a Wellcome Trust surgical research fellowship.

\section{References}

1 Grant DAW, Jones P, Hermon-Taylor J. The biliary excretion of enterokinase in rats. Studies in normal, chronic ethanol-maintained and cirrhotic rats. Biochem J 1981; 198: 315-9.

2 Thomas P. Studies on the mechanisms of biliary excretion of circulating glycoproteins. The carcinoembryonic antigen. Biochem J 1980; 192: 837-43.

3 Leiber CS, Jones DP, DeCarli LM. Effects of prolonged ethanol intake: production of fatty liver despite adequate diets. J Clin Invest 1965; 44: 1009-21.

4 Grant DAW, Magee AI, Hermon-Taylor J. Optimisation of conditions for the affinity chromatography of human enterokinase on immobilised paminobenzamidine. Eur J Biochem 1978; 88: 183-9.

5 Grant DAW, Hermon-Taylor J. Hydrolysis of artificial substrates by enterokinase and trypsin and the development of a sensitive specific assay for enterokinase in serum. Biochim Biophys Acta 1979; 567: 207-15. 
6 Folch J, Lees M, Sloane Stanley GH. A simple method for the isolation and purification of total lipids from animal tissues. J Biol Chem 1957; 226: 497-509.

7 Lieber CS, Spritz N, DeCarli LM. Fatty liver produced by dietary deficiencies: its pathogenesis and potentiation by ethanol. J Lipid Res 1969; 10: 283-7.

8 Lieber CS. Alcohol, protein metabolism and liver injury. Gastroenterology 1980; 79: 373-90.

9 Grant DAW, Hermon-Taylor J. The purification of human enterokinase by affinity chromatography and immunoabsorption. Biochem J 1976; 155: 243-54.

10 Yamashina I. Studies on enterokinase. Arkv Kemi 1956; 9: 225-9.

11 Magee AI, Grant DAW, Hermon-Taylor J. Further studies on the subunit structure and oligosaccharide moiety of human enterokinase. Clin Chim Acta 1981; 115: 241-54.

12 Grant DAW, Magee AI, Meeks D, Regan C, Bainbridge DR, Hermon-Taylor J. Identification of a defence mechanism in vivo against leakage of enterokinase into the blood. Biochem J 1979; 184: 619-26.

13 Morell AG, Gregoriadis G, Scheinberg IH, Hickman J, Ashwell $\mathbf{G}$. The role of sialic acid in determining the survival of glycoproteins in the circulation. J Biol Chem 1971; 246: 1461-67.
14 Hudgin RL, Pricer WE, Ashwell G, Stockert RJ, Morell AG. The isolation and properties of a rabbit liver binding protein specific for asialoglycoproteins. $J$ Biol Chem 1974; 249: 5536-43.

15 Kawasaki T, Ashwell G. Chemical and physical properties of an hepatic membrane protein that specifically binds asialoglycoproteins. $J$ Biol Chem 1976; 251: 1296-302.

16 Thomas $\mathrm{P}$, Toth CA, Zamcheck $\mathrm{N}$. The mechanism of biliary excretion of $\alpha_{1}$-acid glycoprotein in the rat. Gastroenterology 1981; 80: 1302.

17 Renston RH, Maloney DG, Jones AL, Hradek GT, Wong KY, Goldfine ID. Bile secretory apparatus: evidence for a vesicular transport mechanism for proteins in the rat using horseradish peroxidase and ${ }^{125} \mathrm{I}$ insulin. Gastroenterology 1980; 78: 1373-88.

18 deDuve C, Wattiaux R. Functions of lysosomes. Ann Rev Physiol 1966; 28: 435-92.

19 Seeff LB, Zimmerman HJ. Relationship between hepatic and pancreatic disease. In: Popper $\mathbf{H}$, Schaffner F, eds. Progress in liver disease, V. New York: Grune and Stratton, 1976: 590-608.

20 Storck G, Pettersson G, Edlund Y. A study of autopsies upon 116 patients with acute pancreatitis. Surg Gynec Obstet 1976; 143: 241-5. 